Тусупбаев Н. К., д.т.н., член-корр.КазНАЕН

AО "Институт металлургии и обогащения" г. Алматы, Казахстан E-mail: nesipbay@mail.ru ORCID ID 0000-0002-6110-0772

Батырбаева А., Школа-гимназия №139 им. А. Байтурсынова

E-mail: ayaulim.bb@mail.ru

Амантай Н., Школа-гимназия №139 им. А. Байтурсынова

Мухатаева Н., Школа-гимназия №139 им. А. Байтурсынова

E-mail:naziken_68@mail.ru

Ержанова Ж.А., АО "Институт металлургии и обогащения" г. Алматы, Казахстан

E-mail: jadu76@mail.ru ORCID ID 0000-0003-3917-1600 Билялова С., АО "Институт металлургии и обогащения" г. Алматы, Казахстан

E-mail: salta.b-79@mail.ru ORCID ID 0000-0002-6326-4287

\title{
ИЗУЧЕНИЕ ПРОЦЕССА СГУЩЕНИЯ И ФИЛЬТРАЦИИ СВИНЦОВО- ЦИНКОВЫХ КОНЦЕНТРАТОВ В ПРИСУТСТВИИ НЕИОНОГЕННЫХ ПОЛИМЕРОВ И ИХ СМЕСИ С АНИОННЫМИ ПОЛИЭЛЕКТРОЛИТАМИ
}

Аннотация. Изучена флокулящия флотационных концентратов в присутствии анионных полиэлектролитов, при фильтрации свинщового концентрата с плотностью 45\% был получен положительный эффект при расходе флокулянта карбоксиметилцеллюлозы (КМЦ) 28-85 2/m. В случае фильтрации ициковых концентратов с плотностью 41 \% хорошие результаты были получены при расходе 44-104 г/m. На примере суспензии отхоооов флотации исследованы закономерности кинетики флокуляции в присутствии индивидуальных неионогенных полимеров ( ПЭГ, ПЭО и ПВС). С ростом концентрации электролита в системе скорость флокуляции по сравнению со скоростью коагуляиии вначале возрастает, затем все более снижсается. Проведень опыты по фильтрации свинцового и ичнккового концентратов на лабораторном вакуум-фильтре в присутствии смесей неионогенных полимеров (ПЭО, ПЭГ и ПВС) и анионных флокулянтов (ПАК, ПМАК и КМЦ). В присутствии смесей ПЭО + КМЦ наибольшая скорость осаждения свинцового конщентрата составила 2,6 см/сек, а в случае цинкового $-2,1$ см/сек. При использовании смесей ПЭО + ПАК и ПЭО + ПМАК максимальная скорость осаждения свиниового и иинкового кониентратов колебалась в пределах 1,4-1,8 см/сек. При фильтрации свинцового концентрата с плотностью 48\% был получен положительный эффект при расходе флокулянта ПЭО + КМЦ 22-91 г/m. В случае фильтрации ичинковых концентратов с плотностью $42 \%$ хорошие результаты были получены при расходе 31-112 г/m.

Ключевые слова: свинцовый и иинковый концентраты, неионогенные полимеры, анионные флокулянты, флокулячия, сгущение, фильтращия.

Tusupbaev N.K., ${ }^{1}$ Yerzhanova Zh.A ${ }^{1 *} \&$ Bilyalova S.M. ${ }^{1}$ ${ }^{1}$ Institute of Metallurgy and Enrichment, Almaty, the Republic of Kazakhstan E-mail*: jadu76@mail.ru

Mukhatayeva N., ${ }^{2}$ Batyrbaeva $\mathrm{A}^{2 *}$ \& Amantai N. ${ }^{2}$ School-gymnasium № 139 after named A. Baytursynov E-mail*: ayaulim.bb@mail.ru

\section{STUDY OF THE CONCENTRATION AND FILTRATION OF LEAD-ZINC CONCENTRATES IN THE PRESENCE OF NON-INOGENEOUS POLYMERS AND THEIR MIXTURES WITH ANION POLYELECTROLITES}


Annotation. The flocculation of flotation concentrates in the presence of anionic polyelectrolytes was studied, while filtration of lead concentrate with a density of $45 \%$, a positive effect was obtained with the consumption of the flocculant carboxymethyl cellulose (CMC) $28-85 \mathrm{~g} / \mathrm{t}$. In the case of filtration of zinc concentrates with a density of $41 \%$, good results were obtained at a flow rate of 44-104 $\mathrm{g} / \mathrm{t}$. The flotation kinetics regularities in the presence of individual non-ionic polymers (PEG, PEO and PVA) are studied using the example of flotation waste suspension. With increasing electrolyte concentration in the system, the flocculation rate in comparison with the coagulation rate first increases, then decreases more and more. Experiments have been conducted on the filtration of lead and zinc concentrates on a laboratory vacuum filter in the presence of mixtures of nonionic polymers (PEO, PEG and PVA) and anionic flocculants (PAA, PMAC and CMC). In the presence of PEO +CMC mixtures, the maximum sedimentation rate of the lead concentrate was $2.6 \mathrm{~cm} / \mathrm{sec}$, and in the case of zinc concentrate $-2.1 \mathrm{~cm} / \mathrm{sec}$. When mixtures of PEO + PAA and PEO + PMAC were used, the maximum sedimentation rate of lead and zinc concentrates ranged from 1.4 to $1.8 \mathrm{~cm} / \mathrm{sec}$. When the lead concentrate was filtered with a density of 48\%, a positive effect was obtained with the consumption of the flocculant PEO +CMC $22-91 \mathrm{~g} / \mathrm{t}$. In the case of filtration of zinc concentrates with a density of $42 \%$, good results were obtained at a flow rate of $31-112 \mathrm{~g} / \mathrm{t}$.

Keywords: lead and zinc concentrates, non-ionic polymers, anionic flocculants, flocculation, thickening, filtration.

\section{Введение.}

В процессе обогащения и выплавки металлов образуются отходы, утилизация которых сегодня стала одной из актуальнейших тем охраны окружающей среды. Причина этому в том, что в отходах металлургии содержаться в большом количестве токсические химические вещества. Потому, тонны отходов металлургического производства, количество которых исчисляется миллиардами, являются немалой экологической проблемой для Казахстана [1, 2, 3].

В последнее время внимание к факторам, влияющим на эффективность применения флокулянтов в процессах обезвоживания на обогатительных фабриках продолжает увеличиваться в связи с возрастающей потребностью в использовании флокулянтов. Эффективность применения флокулянтов в значительной степени зависит от времени года, химического состава воды, гранулометрического, фракционного и качественного составов шламов, в связи с чем потребность в изучении закономерностей протекания процесса флокуляции при изменении вышеперечисленных факторов как никогда высока [4].

При анализе представленных в научно-технической литературе практических и теоретических исследований, касающихся темы обезвоживания продуктов обогащения полезных ископаемых , можно заметить, что наиболее действенным способом повышения эффективности процессов разделения твердой и жидкой фаз (осветления, сгущения, фильтрования) является применение синтетических полимерных флокулянтов. В современной практике флокулянты получают все более широкое применение в указанных операциях на углеобогатительных фабриках (УОФ) России и за рубежом [5, 6]. Наибольшего количества флокулянтов требуют операции сгущения и обезвоживания тонкодисперсных шламов или отходов флотации в специальных аппаратах различного конструктивного исполнения $[6,7]$.

На процесс флокуляции влияет большое количество разнообразных факторов, а сам процесс носит системный характер [8].

Для процессов сгущения первостепенную роль играет способность глиносодержащих пульп при определенных условиях образовывать агрегативно и седиментационно устойчивые системы. Глинистые минералы при контакте с жидкой 
фазой активно адсорбируют на своей поверхности полярные молекулы последней, что приводит к образованию на поверхности частиц сольватно-гидратационного слоя, пагубно влияющего на способность частиц к коагуляции и осаждению $[9,10]$.

Необходимо учитывать, что значительная часть труд но осаждающихся твердых частиц в таких системах может находиться в коллоидном состоянии. Агрегативная устойчивость каждой из этих частиц обеспечивается электрическими зарядами на ее поверхности. Они препятствуют слипанию заряженных частиц с образованием более крупных агрегатов и их последующему осаждению. От величины заряда коллоидной частицы зависит расстояние, на которое коллоидные частицы могут приближаться друг к другу. Агрегативная и седиментационная устойчивость обуславливаются совокупностью большого количества факторов: физико-химическими свойствами твердой и жидкой фазы суспензии, степенью дисперсности материала, удельной площадью поверхности частиц и т.п. Для определения характеристики коллоидной системы требуется знание природы коллоидных частиц и величины их заряда $[11,12]$.

Экспериментальная часть. Изменение скорости седиментации суспензий свинцового и цинкового концентратов в присутствии смесей неионогенных полимеров (ПЭО, ПЭГ и ПВС) и анионных флокулянтов (ПАК, ПМАК и КМЦ) оценивали следующим образом: суспензию определенной концентрации помещали в градуированный мерный цилиндр на 1000 мл, прибавляли необходимое количество флокулянта и после перемешивания наблюдали за перемещением границ раздела суспензия - прозрачный раствор во времени. На основании полученных данных вычисляли скорость оседания суспензии и определяли эффективность флокулирующего действия исследованных реагентов.

Показано, что в присутствии смесей ПЭО + КМЦ наибольшая скорость осаждения свинцового концентрата составила $2,6 \mathrm{~cm} /$ сек, а в случае цинкового - 2,1 cм/сек. При использовании смесей ПЭО + ПАК и ПЭО + ПМАК максимальная скорость осаждения свинцового и цинкового концентратов колебалась в пределах 1,4 - 1,8 см/сек. Поэтому лучшим флокулянтом для данной системы является ПЭО + КМЦ.

Параллельно проводили контрольные опыты без добавления флокулянтов. О скорости осаждения частиц дисперсной фазы судили по изменению во времени границы, разделяющей в мерном цилиндре объемом $500 \mathrm{~cm}^{3}$ столб осветленной жидкости и концентрируемой суспензии воды. Количественной характеристикой флокулирующего эффекта (D) служил параметр $\quad D=\frac{v}{v_{0}}-1$, где, $v$ и $v_{\text {o }}$ - скорость осаждения дисперсной фазы концентратов соответственно в присутствии и в отсутствии флокулянта. Полученные данные приведены на рисунках 1, 2 .

Была оценена флокулирующая способность изученных флокулянтов в зависимости от концентрации и молекулярной массы в турбулентном режиме. Как показано на рисунках 1, 2 с увеличением дозы полимера флокулирующий эффект проходит через максимум, т.е. дальнейший рост концентрации флокулянта приводит к стабилизации системы. Зафиксированное на этих рисунках усиление флокулирующего эффекта (D) при увеличении дозы и молекулярной массы флокулянта объясняется увеличением концентрации макромолекулярных мостиков вследствие одновременной адсорбции отдельных макромолекул на двух и более частицах дисперсной фазы.

Это обстоятельство, очевидно, связано с более эффективной адсорбцией отрицательно заряженных макромолекул изученных флокулянтов на частицах дисперсной фазы свинцового и цинкового концентратов. 
Как видно из рисунков 1, 2 флокулянт ПЭО+КМЦ имеет наибольшие значения D, по сравнению с другими образцами. Это наводит на мысль о том, что определяющим параметром флокулянта является молекулярная масса.

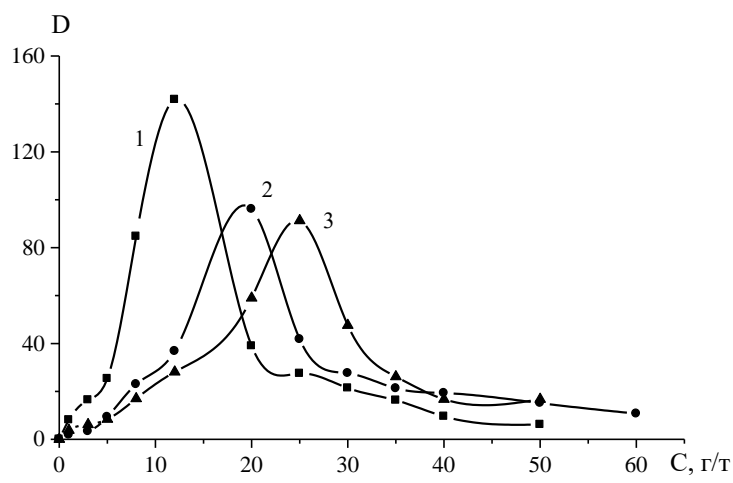

1 - ПЭО + КМЦ; 2 - ПЭО + ПАК; 3 - ПЭО + ПМАК

Рисунок 1 - Изменение флокулирующего эффекта (D) суспензии свинцового концентрата с содержанием твердого 45,5 г/л в присутствии различных флокулянтов при турбулентном режиме перемешивания

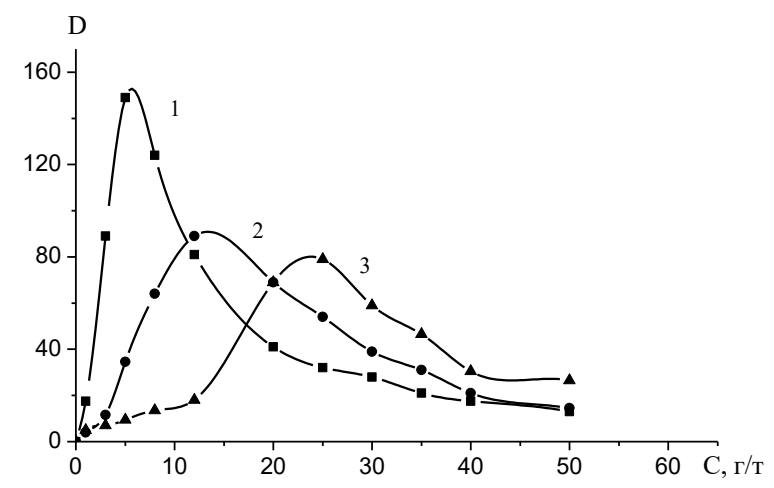

$1-$ ПЭО + КМЦ; 2 - ПЭО + ПАК; 3 - ПЭО + ПМАК

Рисунок 2 - Изменение флокулирующего эффекта (D) суспензии цинкового концентрата с содержанием твердого 32,7 г/л в присутствии различных флокулянтов при турбулентном режиме перемешивания

Таким образом, полученные результаты позволили рекомендовать провести опытнопромышленные и промышленные испытания флокулянта ПЭО + КМЦ в тех отраслях промышленности Казахстана, где необходимо сгущение от мелкодисперсных и шламистых продуктов.

Проведены опыты по фильтрации свинцового и цинкового концентратов на лабораторном вакуум-фильтре в присутствии смесей неионогенных полимеров (ПЭО, ПЭГ и ПВС) и анионных флокулянтов (ПАК, ПМАК и КМЦ). Фильтр представляет металлическую воронку конической формы, внутри которой припаяны или вставлены в уровень с ее бортами радиальные перегородки. На воронку укладывали круг фильтровальной ткани большего диаметра, чем воронка. Ткань затягивали зажимным кольцом, обработанным также на конус. Воронку трубкой соединяли с ресивером, который с другой стороны присоединен к вакуум-насосу. На ресивере установлен 
манометр. Фильтр соединяли с ресивером через тройник с двумя кранами. Один из отводов тройника соединен трубкой с выхлопной трубой вакуум-насоса, на которой выше присоединения трубки также установлен кран.

Для опытов пульпу питания сгустителя свинцового и цинкового концентратов помещали в сосуд большего диаметра, чем фильтр. Пульпу поддерживали во взвешенном состоянии перемешиванием механической мешалкой. Проверив все соединения трубок, основной кран закрыли, а другие краны открыли, запустили в действие вакуум-насос и фильтр погрузили в пульпу. Одновременно с помощью секундомера отмечали продолжительность наращивания кека на фильтре. Через определенный промежуток времени фильтр вынимали и через кек просасывали воздух. По истечении срока просасывания воздуха основной кран открыли, а другие краны закрыли и кек отдували в приемник. После продувки в течение определенного времени снова закрыли основной кран, открыли другие краны, и цикл повторили снова.

Определение производительности фильтра. Фабричный цикл фильтрации состоит из трех фаз: наращивания кека на фильтре в пульпе, сушки кека просасыванием через него воздуха и отдувки кека. В зависимости от глубины корыта фильтра и степени его заполнения распределение времени на операции за один оборот фильтра может быть различным; его принимали исходя из условий работы данной фабрики. Например, фильтр делает один оборот за 5 мин. и на наращивание кека идет $21 \%$ времени всего цикла, т.е. 1,2 мин., а на просасывание воздуха $55 \%$, т.е. 3 мин., на отдувку $10 \%$, или 0,6 мин. Исходя, из этого намечали продолжительность отдельных операций при проведении лабораторного опыта. Повторив цикл получения кека на лабораторном фильтре несколько раз, взвешивали сначала сырой кек, затем высушенный при температуре $110^{\circ} \mathrm{C}$. Зная массу сухого кека $\mathrm{P}, \Gamma$, фильтрующую площадь $\mathrm{S}, \mathrm{cm}^{2}$ и продолжительность одного цикла рассчитывали производительность фильтра.

Установлено, что при фильтрации свинцового концентрата с плотностью 48\% был получен положительный эффект при расходе флокулянта ПЭО + КМЦ 22-91 г/т. В случае фильтрации цинковых концентратов с плотностью $42 \%$ хорошие результаты были получены при расходе 31-112 г/т.

При сравнении с контрольными опытами без использования реагентов, при добавлении флокулянта ПЭО + КМЦ производительность фильтров при фильтровании свинцового концентрата увеличилась на 34 \% при влажности 14-17 \%, а цинкового концентрата - на 24 \% при влажности 16-19,5\%.

\section{СПИСОК ИСПОЛЬЗОВАННЫХ ИСТОЧНИКОВ}

1. Кенжалиев Б.К., Требухов С.А., Володин В.Н., Требухов А.А., Тулеутай Ф.Х., Извлечение селена из промпродуктов металлургического производства. Журнал: Комплексное использование минерального сырья. ОСТОВЕR 2018. https://doi.org/10.31643/2018/6445.30

2. Bagdaulet Kenzhalyevich Kenzhaliyev, Renata Ramilevna Iskhakova and Zamzagul Duisenovna Dosymbayeva. Sorption extraction of noble and non-ferrous metals from process leaching solutions, American Journal of Applied Sciences. Volume 12, Issue 11, P. 875-884. 2015. https://doi.org/10.3844/ajassp.2015.875.884

3. K. Kh. Nussupov, N. B. Beisenkhanov, I. K. Beisembetov, Bagdaulet Kenzhaliyev, B. Zh. Seitov, E. Dulatuly, D. I. Bakranova. The formation of TixNy and TaxNy-based diffusion barriers. Materialstoday: Proceedings, 2017. Volume 4, Issue 3, Part A, 2017, P. 4534-4541 https://doi.org/10.1016/j.matpr.2017.04.026

4. Фролов Д.В. Исследование и обоснование подходов к оптимизации процессов сгущения угольных шламов // Вестник Кузбасского государственного технического университета. 2018.-№2. - C.61-69. 
5. Glover, S.M. Polymer Molecular Weight and Mixing Effects on Floe Compressibility and Filterability/ S.M. Glover,Y.D. Yan, G.J.Jameson and S.Biggs // VI World Congress of Chemical Engineering.Melbourne. -2001.

6. The Usage of flocculants for the Processes of Thickening and Dewatering of a thin coal sludges Frolov V.S., Merkusheva L.N., Frolov D.V., Sidorov A.V. // XVIII International Coal Preparation Congress, Saint-Petersburg Mining University Volume 2, 28 June - 01 July 2016 Saint-Petersburg, Russia.

7. Frolov V.S. Application of Magnafloc Flocculants in the Process of Thickening and Dewatering at Coal Preparation Plants // XVII. International COAL preparation congress. 1-6 october 2013. Istanbul. Turkey. P. 449-452.

8. Gregory, J. The Effect of Polymers on Dispersion Properties / John Gregory // edited by Th. F. Tadros. -London: Academic Press, 1982. -P.301.

9. Бауман А.В Проблемные вопросы проектирования схем сгущения и водооборота обогатительных фабрик // Обогащения руд.2016. №3. - С.58-62.

10. Бауман А.В. О модернизации отечественных радиальных сгустителей.// Обогащения руд. 2013.-№1. - C.44-49.

11. Новаков, И. А., Орлинсон Б. С. Полимеры на основе производных адамантана: синтез, свойства, направления практического использования: монография - Волгоград : РПК "Политехник", 2005. - С.95.

12. Тусупбаев Н.К., Ержанова Ж.А., Билялова С.М., Тойланбай Г.А., Флокуляция суспензии кварца в присутствии суперфлокулянтов различного заряда. Журнал: Комплексное использование минерального сырья. October 2018. https://doi.org/10.31643/2018/6445.26 